\title{
Cause and Management of Calcified Left Ventricular Hyper trabeculation / Noncompaction
}

\author{
Josef Finsterer $^{1}$ and Claudia Stöllberger ${ }^{2}$ \\ ${ }^{1}$ Krankenanstalt Rudolfstiftung, Austria \\ ${ }^{2}$ Medical Department with Cardiology and Intensive Care Medicine, Krankenanstalt Rudolfstiftung, Austria \\ *Corresponding author: Josef Finsterer, MD, PhD, Postfach 20, 1180 Vienna, Austria, Europe
}

Received: 海 December 17, 2018

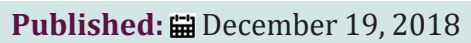

\section{Letter to Editor}

In a recent article, Pipitone et al. [1] reported about a fetus with calcified left ventricular hypertrabeculation / noncompaction (LVHT) and persistence of the abnormality after delivery [1]. We have the following comments and concerns regarding this paper. LVHT is frequently associated with other cardiac abnormalities or diseases of organs other than the heart. Was the index patient or any of the relatives investigated for multisystem involvement? Was there any indication for cerebral, ocular, otologic, endocrine, cardiac, intestinal, renal, haematological, or cutaneous abnormalities in addition to LVHT?

LVHT is frequently associated with severe complications, such as heart failure, ventricular arrhythmias and sudden cardiac death, or stroke / embolism. Was the history of the index patient or of any of his relatives positive for any of these complications? LVHT is frequently associated with neuromuscular disorders (NMDs) or chromosomal abnormalities [2]. Was the individual or family history positive for NMD or a chromosomal defect or were there any clinical indications for a NMD in the index case or any of his relatives? Was there any indication for dysmorphism? LVHT frequently occurs familiarly [2]. Was the mother or any other firstdegree relative investigated for LVHT and which were the results? LVHT is not a congenital abnormality in each case. Particularly, in pregnant women, athletes, or some NMDs, LVHT has been shown to develop during postnatal life (acquired LVHT) [2-10].

Myocardial calcification in LVHT patients has been only reported in a patient with MBL-deficiency [3], local myocardial dysregulation [4], and coronary microcirculatory dysfunction [5]. The cause of the calcifications may not only be infectious, autoimmune, or hypoxic but could be also degenerative or due to MBL-deficiency [9]. Calcification of the basal ganglia have been found in patients with LVHT [7]. Were calcifications found in the presented patient at any site other than the heart? Was the gravida living together with animals? Was a protozoonosis (toxoplasmosis) or helminthosis excluded as the cause of the calcifications? Was there eosinophilia in the index patient or his mother? Which were the levels of calcium, phosphate, parathormone, and calcitonin? Was the history in the index patient or his mother positive for endocarditis or myocarditis? Was the mother a smoker, a drug abuser or was she HIV-positive? Was the psychomotor development normal in the index case? Which was the AGPAR score at birth? Which was the reason for the reduced birth weight? Overall, basic work-up of index cases with LVHT and their family members is a prerequisite to contribute to the clarification of the still unknown pathogenetic background of LVHT. Not to miss the point of prophylactic measures against possible complications of LVHT, close and regular follow-up investigations of index cases are recommended.

\section{References}

1. Pipitone S, Curcio P (2014) A case of fetal myocardial calcifications andnoncompaction: an unitary hypoxic pathogenesis? Ultrasound Obstet Gynecol 45(2).

2. Stöllberger C, Finsterer J, Blazek G (2002) Left ventricularhypertrabeculation/noncompaction and association with additional cardiac abnormalities and neuromuscular disorders. Am J Cardiol 90(8): 899-902.

3. Finsterer J, Stöllberger C, Wolf HM (2011) Heterozygous promotor haplotype LXA/LYB in MBL-deficiency associated with myopathy and left ventricular hypertrabeculation/noncompaction. Ir J Med Sci 180(4): 909-911.

4. Chow V, Ridley L, Sindone A, Kritharides L (2012) Caseous calcification associated with left ventricular noncompaction: a multimodality diagnostic approach. Int J Cardiol 155(2): 29-31. 
5. Nil M, Mori K, Yuasa Y, Ichida F (2003) Isolated noncompaction of myocardium associated with calcification in the interventricular septum. Pediatr Cardiol 24(6): 591-594.

6. Finsterer J, Stollberger C, Mölzer G, Winkler-Dworak M, Blazek G (2008) Cerebrovascular events in left ventricular hypertrabeculation/ noncompaction with and without myopathy. Int J Cardiol 130(3): 344348.

7. Finsterer J, Stöllberger C, Feichtinger H (2008) Noncompaction and endocarditis in suspected mitochondrial disorder. Int J Cardiol 123(3): 45-47.
8. Chow V, Ridley L, Sindone A, Kritharides L (2012) Caseous calcification associated with left ventricular noncompaction: a multimodality diagnostic approach. Int J Cardiol 155(2): 29-31.

9. Finsterer J, Stöllberger C, Wolf HM (2011) Heterozygous promotor haplotype LXA/LYB in MBL-deficiency associated with myopathy and left ventricular hypertrabeculation/noncompaction. Ir J Med Sci 180(4): 909-911.

10. Nil M, Mori K, Yuasa Y, Ichida F (2003) Isolated noncompaction of myocardium associated with calcification in the interventricular septum. Pediatr Cardiol 24(6): 591-594.

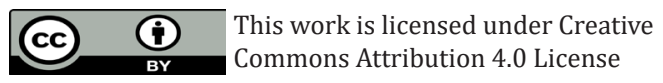

To Submit Your Article Click Here:

Submit Article



